\title{
Recent Advances in the Management for Genitourinary Syndrome of Menopause
}

\author{
${ }^{1}$ Seetesh Ghose, ${ }^{2}$ Palai Pallavee, ${ }^{3}$ Rupal Samal
}

\begin{abstract}
Menopausal women suffer from various symptoms related to genital tract and urinary tract. These symptoms are due to low estrogen level at this stage of life. Although this is commonly termed as vulvovaginal atrophy or atrophic vaginitis, it does not reflect the presence of underlying urinary symptoms. So, to encompass full spectrum of symptoms, a broad term like genitourinary syndrome of menopause (GSM) is being used more recently in place of vulvovaginal atrophy or atrophic vaginitis. It describes various symptoms and signs of menopause which include genital symptoms, such as dryness, irritation and burning, urinary symptoms like urgency, dysuria, and recurrent urinary tract infection (UTI) and sexual symptoms like lack of lubrication and discomfort or pain. Wide range of treatments are available which include nonhormonal black cohosh, a phytoestrogen, lubricants or moisturizers for symptom relief, vaginal estrogen therapies, systemic hormonal therapies (HTs), tissuespecific estrogen complex [combination of selective estrogen receptor modulators (SERM) and estrogen] besides newer therapies. These newer therapy include laser, radiofrequency (RF), and magnetic therapy. As the GSM have negative impact, awareness, recognition and appropriate treatment of GSM will improve the quality of postmenopausal women.
\end{abstract}

Keywords: Genitourinary syndrome of menopause, Menopause, Vulvovaginal atrophy.

How to cite this article: Ghose S, Pallavee P, Samal R. Recent Advances in the Management for Genitourinary Syndrome of Menopause. J South Asian Feder Menopause Soc 2018;6(1):65-68.

Source of support: Nil

Conflict of interest: None

Date of received: 10 January 2018

Date of acceptance: 27 January 2018

Date of publication: August 2018

\section{INTRODUCTION}

Vulvovaginal atrophy or atrophic vaginitis was the term commonly used until recently to describe the symptoms

\footnotetext{
${ }^{1}$ Professor and Head, ${ }^{2}$ Professor, ${ }^{3}$ Associate Professor

${ }^{1-3}$ Department of Obstetrics \& Gynecology, Mahatma Gandhi Medical College \& Research Institute, Puducherry, India

Corresponding Author: Seetesh Ghose, Professor and Head Department of Obstetrics \& Gynecology, Mahatma Gandhi Medical College \& Research Institute, Puducherry, India, Phone: +914132615449458, e-mail: seetesh@mgmcri.ac.in
}

and signs related to genitourinary system following menopause. Although atrophic vaginitis signifies inflammation or infection of vagina, it does not form a primary change associated with menopause. In addition, it does not reflect the underlying lower urinary tract symptoms, which are related to menopause. Besides all of the above, the words vulva and vagina are not commonly used in social discussion or media. ${ }^{1}$ Therefore, the Board of Directors of the International Society for the Study of Women's Sexual Health and the Board of the North American Menopause Society (NAMS) emphasized the introduction of a new terminology in place of terms like vulvovaginal atrophy and atrophic vaginitis in a terminology consensus conference which was organized in 2013. The term GSM was finally approved in 2014.

The GSM narrates various menopausal symptoms and signs related to changes in the vulva, vagina, and lower urinary tract as well. The genital symptoms of GSM include dryness, burning, and irritation, and sexual symptoms include lack of lubrication, discomfort or pain, and urinary symptoms include dysuria, urgency, and recurrent UTI. With the increasing life expectancy, women spend considerable period of life in postmenopausal period. Hypo-estrogenic state of this period causes many health problems. Of these problems, vasomotor symptoms like hot flushes and night sweating often get better over the time, whereas genitourinary symptoms which are chronic, rarely resolve of its own and rather worsen, if left untreated. ${ }^{2}$

Although these manifestations are not a deathly illness, they worsen and have deep impact on the quality of life (QOL) of postmenopausal women. It affects not only their self-esteem but also intimacy with their partners negatively. ${ }^{3}$ Moreover, GSM may appear following surgical menopause, use of gonadotropin-releasing hormone agonists, because of cancer treatments like chemotherapy, pelvic radiation, or endocrine therapy. ${ }^{4}$ So, taking care of postmenopausal women with genitourinary symptoms has evolved as an important problem in our society.

\section{PREVALENCE OF GSM}

\section{Vulvovaginal Symptoms and Sexual Dysfunction}

In a study by Iosif and Bekassy, $15 \%$ reported itch, discharge, whereas $38 \%$ reported dyspareunia and vaginal dryness. Stenberg et $\mathrm{al}^{6}{ }^{6}$ in a cohort study, reported that 
among 59\% sexually active women, $43 \%$ had vaginal dryness and $10 \%$ had sensation of vaginal burning. In cohort surveys of Western populations, 45 to $63 \%$ of postmenopausal women mention experiencing vulvovaginal symptoms, vaginal dryness being most common; other symptoms included were vaginal irritation, dyspareunia, itching sensation, and vaginal spotting during intercourse. ${ }^{3,7,8}$ In a Korean study, $49 \%$ of postmenopausal women had experienced similar symptoms. ${ }^{9}$ Levine et a ${ }^{10}$ reported that vulvovaginal symptoms were four times more common in postmenopausal sexually active women. Among them with vulvovaginal symptoms, $40 \%$ also had overall sexual dysfunction, $34 \%$ arousal difficulties, $24 \%$ lack of desire, whereas 19\% had orgasm difficulties. The Study of Women's Health Across the Nation in the USA reported vaginal dryness to be an important factor associated with pain, arousal, masturbation, physical pleasure, and emotional satisfaction. ${ }^{11}$

\section{Dysfunction of Lower Urinary Tract}

Iosif and Bekassy ${ }^{5}$ in their study showed that $29.2 \%$ had varied degrees of urinary incontinence. Among them, $11.8 \%$ of the women reported stress incontinence, $7.9 \%$ urge incontinence, $9.5 \%$ had mixed incontinence, and $13 \%$ had recurrent UTI. They also reported that $48.8 \%$ had lower genital tract problem. Stenberg et $\mathrm{al}^{6}{ }^{6}$ in a population-based cohort study, reported that $73 \%$ of the women experienced urinary incontinence of which 33\% were of severe degree; $31 \%$ experienced urge incontinence of which $14 \%$ were severe. In a study by Robinson and Cardozo, ${ }^{12}$ the proportion of severe urge incontinence and stress incontinence were 20 and 50\% respectively. The study by Hyun et $\mathrm{al}^{13}$ revealed intrinsic sphincteric dysfunction as a result of altered connective tissue due to hypo-estrogenic state as the prime cause of urinary incontinence in postmenopausal women, whereas anatomical change was the most common responsible factor for urinary incontinence in premenopausal women. Studies have shown that bacteriuria was associated with 15 to $20 \%$ of women aged 65 to 70 years, and 20 to $50 \%$ of women aged $>80$ years. ${ }^{14,15}$

\section{ETIOPATHOLOGY OF GSM}

The hypo-estrogen levels after menopause are directly related to these symptoms. During reproductive life, estrogen receptors are commonly present in the vagina, vulva, urethra, bladder trigone, musculature of the pelvic floor, and endopelvic fascia. But with menopause, their levels decline, which may be restored by treatment with estrogen. Due to hypo-estrogenic state following menopause, the content of collagen, hyaluronic acid, and the levels of elastin reduce. This leads to thinning of the epithelium, altered smooth muscle cell function, increase in connective tissue density, and fewer blood vessels. All these lead to reduce vaginal elasticity, increased vaginal $\mathrm{pH}$, vaginal flora change, and reduced lubrication, which in turn predispose the postmenopausal women to increased vaginal irritation and trauma. ${ }^{16,17}$ Due to its common embryological source, i.e., urogenital sinus, in both genital tract and lower urinary tract, hypo-estrogenic state of menopause is responsible for lower urinary tract symptoms, such as dysuria, urgency, frequency, nocturia, urinary incontinence, and recurrent UTI. ${ }^{12}$

\section{MANAGEMENT OF GSM: THE PRIMARY FOCUS OF TREATMENT IN GSM IS TO RELIEVE SYMPTOMS}

Currently available treatments can be classified into nonhormonal and hormonal. Nonhormonal includes black cohosh which is a phytoestrogen, lubricants or moisturizers for symptom relief, whereas HT consists of local use of estrogen (vaginal cream, tablets, ring), systemic use of estrogen (oral and transdermal), and tissue-specific estrogen complex (combination of SERM and estrogen). However, advancement in the management of GSM includes laser, RF, and magnetic therapy. .

\section{Local Treatment}

\section{Nonhormonal Treatment}

According to NAMS, the nonhormonal lubricants, i.e., water-, silicone-, or oil-based, are the first-line treatment during intercourse for postmenopausal women who suffer from vulvovaginal symptoms. Besides that, longacting, locally active moisturizing agents can decrease $\mathrm{pH}$ of vaginal to premenopausal levels, but they do not ameliorate the vaginal maturation index. ${ }^{4}$ The Society of Obstetricians and Gynecologists of Canada guidelines also affirm that regular topical application of vaginal moisturizers is equally effective to that of vaginal estrogen applied topically for alleviating vulvovaginal symptoms, such as itching, irritation, and dyspareunia. So, it should be recommended to women who wish to avoid the application of estrogen because of health concerns. ${ }^{18}$

\section{Hormonal Treatment}

Short-term application of local estrogen preparations can ameliorate clinical picture of GSM when nonhormonal treatment fails. In the presence of vasomotor symptoms, application of systemic estrogen works better, whereas genitourinary symptoms respond better to local application of estrogen. ${ }^{4}$ Usually, application of vaginal estrogen is safe to use for symptomatic relief of GSM, but it is 
admonished in women with undiagnosed bleeding either from vaginal or uterine. Its use is controversial in women with neoplasia of breast and endometrium, which are estrogen-dependent. ${ }^{19}$

\section{Systemic Treatment}

- Systemic treatment with estrogen or combination of estrogen and progestogen relieves both menopausal symptoms and vulvovaginal symptoms. However, its use to relieve sexual dysfunction in terms of improving libido, arousal is not evidenced by current research. $^{20}$

- Selective ER modulators: Systemic estrogen has stimulatory effects on endometrium and breast, predisposing to malignancy in long-term use. So, use of SERMs was introduced. SERMs have positive effects on targeted tissues, but very little negative influence on other tissues. Of SERMs, the only drug which is approved for the treatment of moderate-to-severe dyspareunia is ospemifene. It has a positive impact on vaginal tissue in postmenopausal women. Its main use is to prevent postmenopausal osteoporosis. ${ }^{21,22}$

- Bazedoxifene (BZA) and conjugated estrogens (CEs): The combination of BZA (20 mg) and CE (0.45 or $0.625 \mathrm{mg}$ ) is a tissue-selective estrogen complex. It has been designed to alleviate vasomotor and dyspareunia, but has no positive effect on vagina. It also averts bone loss while being invulnerable for the endometrium and breast. ${ }^{23,24}$

\section{Newer Treatment Modalities}

\section{Laser Treatment}

A beam of photons with specific wavelength is generated by Laser equipment. Biological tissues, i.e., blood, melanin, and water absorb and react to this beam. This is of two types, i.e., micro-ablative $\mathrm{CO}_{2}$ laser and nonablative Vaginal erbium:yttrium aluminum garnet smooth laser (VEL). The $\mathrm{CO}_{2}$ laser uses the ablative approach. It generates high temperature in the tissue by creating micro-thermal zone (MTZ), which are basically minute holes that are made in the vaginal wall. These MTZs induce shrinkage of tissue, but are not as effective as in initiating neogenesis of collagen. The VEL produces collagen hyperthermia up to $65^{\circ} \mathrm{C}$ in the epithelium and lamina propria, resulting in breaking of the intermolecular crosslinks that stabilize collagen's triple-helix structure, causing rapid contraction of the collagen fibers. This in turn results in shrinkage and greater tissue rigidity and also initiates neocollagenesis in vivo. As it increases the density of the connective tissue, stimulating collagen remodeling and neo-angiogenesis, leading to sub-urethral reinforcement, it is useful for the correction of mild-to-moderate stress urinary incontinence and vaginal canal tightening with subsequent improvement of sexual gratification. The treatment protocol for vaginal tightening and stress urinary incontinence is nicknamed as IntimaLase and IncontiLase respectively. Similarly, the treatment protocol for the pelvic organ prolapse and vaginal atrophy is called ProlapLase and RenovaLase. The IntimaLase protocol involve two 8 to 10 minute sessions at 4- to 6-week interval, whereas IncontiLase involves two 15-minute sessions with the same interval. The protocol for treatment of ProlapLase follows the same principle as that of vaginal tightening and incontinence, but only difference is in the treatment intensity (duration) and the major area treated, i.e., the prolapsed part of the vaginal wall. The ProlapLase protocol requires 3 to 5 sessions at 4- to 6-week interval.

The RenovaLase is based on a concept of milder hyperthermia. Here, the mucosa is warmed up to $45^{\circ} \mathrm{C}$. This causes the stimulation of cell proliferation via heat shock protein activation, an increase of collagen production, and anti-inflammatory action as well. This protocol consists of three sittings at intervals of 3 weeks. ${ }^{25}$

\section{Radiofrequency Wave}

It is another treatment option designed on the principle of bulk heating of tissue to reach the required temperature in collagen for shrinkage and neocollagenesis. However, RF heats the epithelium to a higher temperature, making treatment unpleasant. Moreover, RF needles require local anesthesia. ${ }^{25}$

\section{Functional Magnetic Stimulation}

It has performed well for treatment of all types of urinary incontinence. This causes faster regeneration of muscles and other tissues of pelvic floor, resulting in stronger pelvic floor muscles. It does not require insertion of unpleasant electrode. During the therapy, patients sit dressed in a comfortable chair and a treatment is carried out twice or thrice a week for twenty minutes. As it does not come in contact with the skin directly, the treatment is not painful or uncomfortable and has no side effect. ${ }^{25}$

\section{CONCLUSION}

The GSM is a broad term that encompasses lower urinary tract symptoms and vulvovaginal symptoms related to hypo-estrogenic state. Very few women relate symptoms to menopause or hypo-estrogenic state, whereas most women consider them as part of normal and avoid consulting a gynecologist for that. Although a varied range of accomplished treatment options are available from nonhormonal local application to noninvasive laser 
treatment including local and systemic HT, many women are still diffident to accept HT because of its concern of adverse effects including cancer.

However, since the GSM may have a considerable adverse impact on the QOL of postmenopausal women, they should be made aware of these problems and treated appropriately.

\section{REFERENCES}

1. Portman DJ, Gass ML. Vulvovaginal atrophy terminology consensus conference panel. Menopause 2014 Oct;21(10): 1063-1068.

2. Sturdee DW, Panay N. Recommendations for the management of postmenopausal vaginal atrophy. Climacteric 2010 Dec;13(6):509-522.

3. Nappi RE, Kokot-Kierepa M. Vaginal health: insights, views \& attitudes (VIVA)-results from an international survey. Climacteric 2012 Feb;15(1):36-44.

4. The North American Menopause Society. Management of symptomatic vulvovaginal atrophy: 2013 position statement of The North American Menopause Society. Menopause 2013 Sep;20(9):888-902.

5. Iosif CS, Bekassy Z. Prevalence of genito-urinary symptoms in the late menopause. Acta Obstet Gynecol Scand 1984;63(3):257-260.

6. Stenberg A, Heimer G, Ulmsten U, Cnattingius S. Prevalence of genitourinary and other climacteric symptoms in 61-yearold women. Maturitas 1996 May;24(1-2):31-36.

7. Nappi RE, Kokot-Kierepa M. Women's voices in the menopause: results from an international survey on vaginal atrophy. Maturitas 2010 Nov;67(3):233-238.

8. Kingsberg SA, Wysocki S, Magnus L, Krychman ML. Vulvar and vaginal atrophy in postmenopausal women: findings from the REVIVE (REal Women's VIews of Treatment Options for Menopausal Vaginal ChangEs) survey. J Sex Med 2013 Jul;10(7):1790-1799.

9. Chae HD, Choi SY, Cho EJ, Cho YM, Lee SR, Lee ES, Park HM. Awareness and experience of menopausal symptom and hormone therapy in Korean postmenopausal women. J Menopausal Med 2014 Apr;20(1):7-13.

10. Levine KB, Williams RE, Hartmann KE. Vulvovaginal atrophy is strongly associated with female sexual dysfunction among sexually active postmenopausal women. Menopause 2008 Jul-Aug;15(4 Pt 1):661-666.

11. Avis NE, Brockwell S, Randolph JF, Jr, Shen S, Cain VS, Ory M, Greendale GA. Longitudinal changes in sexual functioning as women transition through menopause: results from the
Study of Women's Health Across the Nation. Menopause 2009 May-Jun;16(3):442-452.

12. Robinson D, Cardozo LD. The role of estrogens in female lower urinary tract dysfunction. Urology 2003 Oct;62 (4 Suppl 1):45-51.

13. Hyun HS, Park BR, Kim YS, Mun ST, Bae DH. Urodynamic characterization of postmenopausal women with stress urinary incontinence: retrospective study in incontinent preand post-menopausal women. J Korean Soc Menopause 2010 Dec;16(3):148-152.

14. Brown JS, Vittinghoff E, Kanaya AM, Agarwal SK, Hulley S, Foxman B. Urinary tract infections in postmenopausal women: effect of hormone therapy and risk factors. Obstet Gynecol 2001 Dec;98(6):1045-1052.

15. Raz R. Urinary tract infection in postmenopausal women. Korean J Urol 2011 Dec;52(12):801-808.

16. Nappi RE, Palacios S. Impact of vulvovaginal atrophy on sexual health and quality of life at postmenopause. Climacteric $2014 \mathrm{Feb} ; 17(1): 3-9$.

17. Tan O, Bradshaw K, Carr BR. Management of vulvovaginal atrophy-related sexual dysfunction in postmenopausal women: an up-to-date review. Menopause 2012 Jan;19(1): 109-117.

18. Johnston SL, Farrell SA, Bouchard C, Farrell SA, Beckerson LA, Comeau $\mathrm{M}$, et al. The detection and management of vaginal atrophy. J Obstet Gynaecol Can 2004 May;26(5):503-515.

19. Nappi RE, Kingsberg S, Maamari R, Simon J. The CLOSER (CLarifying Vaginal Atrophy's Impact On SEx and Relationships) survey: implications of vaginal discomfort in postmenopausal women and in male partners. J Sex Med 2013 Sep;10(9):2232-2241.

20. The North American Menopause Society. The 2012 hormone therapy position statement of: The North American Menopause Society. Menopause 2012;19(3):257-271.

21. Pinkerton JV, Stanczyk FZ. Clinical effects of selective estrogen receptor modulators on vulvar and vaginal atrophy. Menopause 2014 Mar;21(3):309-319.

22. Mirkin S, Komm BS. Tissue-selective estrogen complexes for postmenopausal women. Maturitas 2013 Nov;76(3): 213-220.

23. Archer DF. Tissue-selective estrogen complexes: a promising option for the comprehensive management of menopausal symptoms. Drugs Aging 2010 Jul;27(7):533-544.

24. Lobo RA, Pinkerton JV, Gass ML, Dorin MH, Ronkin S, Pickar JH, Constantine G. Evaluation of bazedoxifene/ conjugated estrogens for the treatment of menopausal symptoms and effects on metabolic parameters and overall safety profile. Fertil Steril 2009 Sep;92(3):1025-1038.

25. Pancholia V. FOGSI connect 2017;3:14-16 